\title{
Guest Editorial Issues, Challenges and Possibilities for Academics and Tutors at Open and Distance Learning Environments
}

\author{
Heather Kanuka \\ Canada Research Chair, e-Learning \\ Athabasca University - Canada's Open University
}

\section{Theme Issue Overview}

Institutions of open and distance learning present a number of special challenges for academics. Development loads and teaching effectiveness are increasing, while traditional demands for research productivity have become a new and/ or increased pressure. The size, complexity, and structure of the networked learning environment at most institutions of open and distance learning have been known to contribute to feelings of isolation and loneliness leading to disengagement experienced by many new and not so new academics. It is possible if we do not address the disconnectedness experienced by many open and distance academics and tutors that detachment to our institutions will occur, resulting in an increased migration to either collaborate with, or work in, other institutions.

Retaining faculty members is not only important for the stability and health of open and distance organizations, but retention - and recruitment - are also issues that institutions of open and distance learning need to be concerned about. The large numbers of senior faculty appointed in the mid 1970s are moving into retirement and/ or later-life careers. It has been estimated that 40 percent of university faculty will retire within the next 10 years. Recruitment and retention of academics is a pressing concern for all universities - but particularly for open and distance universities. The current detached environment may result in a serious employment problem down the road as other traditional universities begin an intensive competition for the best academics. And while these problems exist to some extent at all universities, there is probably no other type of university where building a sense of community is needed.

This theme issue on academics working in open and distance learning environments includes papers based on empirical research, theoretical analysis, and position papers dealing with issues, challenges, and possibilities for academics and tutors at open and distance learning environments. But before I introduce the papers for this theme issue, the editor, Terry Anderson, asked that I briefly outline some new changes made to IRRODL and to talk briefly about a readership survey developed for www.irrodl.org.

\section{Changes to IRRODL Interface}

First, Terry Anderson asked that I relay to you some news - specifically that IRRODL has survived the transition to the Open Journal System (OJS) journal management and publication system. He will be updating the user interface in the near future and hopes that readers have not been overly confused with IRRODL's “new look” and functionality. He advises one major reason 
the change was made was the capacity of OJS to format articles for harvesting using the Open Archives Initiative protocol. Unfortunately, the current generation of harvesters do not like abstracts composed of multiple languages. Thus, Terry has discontinued the publication translated abstracts for the time being. There was also question of the value of being able to read an abstract in a different language other than English, when the full text is only available in English. We also noted that the power of multiple language translation services of English text continues to improve. Terry suggests that Google Translation or AltaVista Babel Fish can be used to translate abstracts or even an entire article into any of the languages currently available. IRRODL did testdrive Babel Fish and Google Translation, and the results were passable (at least as far as Terry's linguistic skills could determine).

Terry anticipates that this change will speed up production, increase harvesting of IRRODL metadata, reduce cost, and only marginally effect non-English speakers. Please let us know if you have concerns or suggestions to improve our multi-lingual services.

\section{Readership Survey}

Next, Terry invites IRRODL readers to participate in an online readership survey. This survey is for quality control purposes only, and any data collected will not be shared beyond that of the immediate editorial team. The purpose for all data collected, is to determine areas where IRRODL needs to improve.

\section{In This Theme Issue}

The article by Monica Shelley, Cynthia White, Uwe Baumann, and Linda Murphy outlines their project based on work at the Open University UK (OUUK). The aim of this project was to describe the attributes and expertise required by tutors of languages in distance education. This articles focuses on issues of definition and research perspective, as well as the advantages and disadvantages of various research approaches and concluding with implications for the on-going professional development of tutors.

The article by Ruth Beyth-Marom, Gal Harpaz-Gorodeisky, Aviad Bar-Haim, and Eti Godder centre around tutors working for The Open University of Israel (OUI), who are often the only academic staff who have direct contact with students and, as such, their activities are crucial to the university. Because tutors are temporary and part time employees however, they have low job security and their academic freedom is limited. These factors can negatively affect tutors' organizational identification, job satisfaction, and motivation. The results of a survey completed by 71 respondents revealed that identification and job satisfaction were well predicted by job importance and organizational attachment, while work motivation was not.

The article by Ilse Fouche examines the experiences of nine tutors at one of the 10 biggest universities in the world, University of South Africa's (Unisa) Reading and Writing Centres. The purpose of this study was to determine to what extent administrative support, professional development support, and colleague support influence tutors' feelings of isolation. Findings from this study revealed that contact with, and collaboration between and amongst, colleagues significantly decreases feelings of isolation.

In the article by Dariya Mukamusoni, the results of a descriptive qualitative case study revealed that faculty members involved in both in service and pre service program are faced with the challenges of heavy workload, with priority given to the pre-service program rather than the distance learning program. A conclusion of this study is that the academic relationship between faculty members and tutors need to be reinforced. Further, course coordinators play a big role in 
effective program operations, and as a link between the distance learning program and pre-service departments and faculties.

The article by Adrian Kirkwood and Linda Price explore the relationship between the use of information and communication technologies (ICT) and learning and teaching through a critique of continuing professional development (CPD) and ICT. They argue against CPD that concentrates on the individual teacher and their use of ICT. They conclude that professional development should focus upon the scholarship of teaching and learning, and must also reflect the wider organisational context within which ICT is managed and used.

The article by Cheuk Fan Ng argues that little research has examined the experiences of academics working in institutions where the faculty is dispersed geographically. Drawing on a literature review of research in telecommuting or teleworking, $\mathrm{Dr} \mathrm{Ng}$ discusses the potential benefits and drawbacks of telecommuting for academics and their families, and the potential opportunities for - and challenges faced - by their distance and online education institutions.

The article by B.J. Eib and Pam Miller argues that the growing number of blended, online, and distance education courses, programs, and degrees offered by institutions of higher education of all types offers challenging new opportunities to re-examine teaching and learning. They describe a carefully designed faculty development program designed to improve the collegial culture at a higher educational organization in Western Canada. The article concludes with suggestions for applying this approach to faculty development in open and distance institutional contexts.

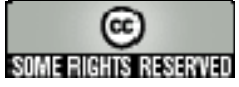

